\title{
Perceptions of Moroccan English Teachers Towards Using Facebook As A Pedagogical and Instructional Tool
}

\author{
Soufiane Soulaymani ${ }^{1}$, Noureddine Alem ${ }^{2}$
}

\begin{tabular}{l} 
ARTICLE INFO \\
\hline Article History: \\
Received 19.06.2018 \\
Received in revised form \\
05.10 .2018 \\
Accepted \\
Available online 01.01 .2019
\end{tabular}

\begin{abstract}
Facebook use between students and teachers is almost ubiquitous and its use for formal academic and educational goals remains contested. Through a quantitative method of research, adopting the online questionnaires as well as paper based ones as tools and the survey as an instrument, this study tries to monitor the use of Facebook as a pedagogical and instructional tool among Moroccan English teachers, in addition to exploring the teachers' attitudes, motivation and perceptions concerning the use of Facebook features in general and the exploitation of Facebook groups, pages, direct live and synchronous as well as asynchronous interactions in particular. Having chosen to work on such a to pic emanates from a personal conviction that the 21 st century teachers are very lucky to have in their possession technological tools, social media and social networks sites, in addition to a well-setenvironment for work. Accordingly, having previously conducted a research study on the attitudes and motivations of English teachers on the use of ICT tools, we concluded that they have a natural predisposition, and thus, they can develop their professional skills, which surely will have positive repercussions on the teaching and learning process. Students will benefit from their knowledge and motivation and will be themselves motivated to learn the way their teachers are doing.
\end{abstract}

Keywords: ${ }^{1}$

Facebook pedagogical use, teaching, social networks, technological motivation, Moroccan English Teachers.

\section{INTRODUCTION}

The accelerated pace of technological development in the world invited to the renovation of educational systems, especially of those of the countries of the South, so that they can improve the quality of teaching and learning for the development of skills through the effective use of the technologies of information and communication (ICT). Indeed, the transformation of the world towards the information society or to the knowledge society has a profound impact on education systems. In fact, the educational systems of all countries are called to expand, relax and improve their relevance and their quality at all levels. This way, ICTs are seen by several observers, as a means to address these challenges (Guttmann, 2003). Certainly, now where ICT is moving extremely fast, an exhaustive census of their practices on the part of teachers for educational purposes would be difficult. Indeed, there are multitudes of possibilities for educational uses of ICT, which grow continually. ICT can be used for research, formatting, processing and exchange of information. They can also support computer-assisted instruction and enable the development of experiences by simulation devices. The web site EDUCNET, for example, proposed a typology of the educational uses of ICT in five categories namely: ICT to Exchange, communicate, collaborate and cooperate, ICT to produce, create and publish, ICT for search and document, ICT for training and to teach ICT to animate and organize (As cited by Josianne Basque and Karin Lundgren Cayrol, 2002).

Similarly, Ertmer (1999) has highlighted two major categories of obstacles. Firstly, the extrinsic obstacles of first-rate, on issues related to access, time, support, resources and training, and, on the other hand, intrinsic barriers called second order indicators. As examples, the attitudes, beliefs, practices and the resistance of teachers. Further than just integrating ICT tools in education and watching the effects on teachers and students, there is nowadays a whole challenge on exploiting social networks and the social media in accompanying these students and teachers in the process of teaching and learning all over the world. It has become a necessity now adays to understand and to enlighten the brains of many responsible educational agents and to let them be conscious about the pedagogical as well as the instructional uses of such media and networks, namely Facebook, Twitter and WhatsApp.

Accordingly, like any teaching method, the integration of social networks into the classroom has several advantages. In order to reach and motivate young people today, there is a need to update and adapt

\footnotetext{
Faculty of Letters and Humanities, Mohammed Ist University, Oujda, Morocco English Department \& CUNEL Laboratory soulaymanisoufyan@gmail.com ,orcid.org/0000-0001-6817-8911

2 Faculty of Letters and Humanities, Mohammed Ist University, Oujda, Morocco, Noureddine.alem@gmail.com
} 
traditional teaching methods to make them more relevant. The use of a new pedagogical approach in relation to the interests of students can really be a source of motivation to go to school and participate actively in the classroom. The virtual world is, in a way, the new reality of young people these days. Therefore, we must not overlook the many possibilities of the technologies that young people are offering. In addition, students will be more open to learning if they feel that the teaching methods used by teachers directly affect them. It would be a question of demonstrating to young people that entertainment can turn into a true pedagogical method. However, before we could use such methods for teaching, it would be necessary primarily to consider the introduction of technology courses in primary schools, both to inform children and teachers. These courses could be used, among other things, to help young people to have a better discernment in relation to the use they make of the Internet in general, but also in a more precise and targeted way. Indeed, it would be a question of teaching young people to have a good critical mind about the information that is conveyed in social networks. Subsequently, as Nicholas Bramble mentions in his article "Facebook must enter the school", technology courses at the school would serve to:

"Teach young people how to use word processing, Web design, and video production software." He also stresses that this would certainly help to "prevent young people at risk at school, and eventually help them find employment."

To return to the potential benefits of social netw orks, it is certain that they represent an alternative way of exchanging information. They can also be used to enhance communication in an original way between members of the same class. For example, if a student wishes to receive an answer to a question that annoys him or prevents him from advancing his homew ork, he could write it on the social network of his class or school. In this way, he would quickly receive explanations from other students or even from the teacher. On the other hand, the teacher could ask the students to publish some text on the class site so that they can get more ideas and read the texts of their friends. Moreover, the teacher can encourage children to write comments, make feedback, highlight errors that have been forgotten...etc.

\section{Significance of the study}

This research study is actually of considerable importance, since it follows a logical thinking in approaching the question of exploring the possibility of using Facebook as a pedagogical and ins tructional tool for the teaching of the English language by Moroccan English teachers. It is done for a number of reasons:

(-) It will assist educational administrators and policy makers in thinking about revolutionary w ays and methods to use, aiming at improving the level of teaching and taking a step ahead.

(-) Students will be granted communication and networking benefits that can be an improvement and an enhancement to their education as well as to their social interactions.

(a) To my knowledge, It will be considered the first research study in Morocco to try to explore this topic, taking into consideration several aspects that are related to the teachers themselves on the one hand, and to the specificity of the social network - Facebook- on the other hand.

๑ It will give an opportunity to compare the views of teachers from many educational backgrounds on the importance of the social network, namely Facebook, as a tool that can serve pedagogically to help teachers and students to better learn, via its platform and advanced functions.

A large number of school headmasters and teachers are daily dealing with the pros and cons of technology integration in their schools (Holladay, 2011). In the coming chapter, a modest review of literature on social networks, social media as well as the use of Facebook in teaching and learning and as an instructional tool will be examined. This study targets the utilization of Web 2.0 technologies, specifically social networks and most precisely Facebook, as a pedagogical tool by Moroccan English teachers. While such technological tools have been inappropriately used by many students (Aricak, 2009), it is expected that via a more appropriate use by teachers and students, they will gain academic and social benefits. It is also the purpose of this study to show those teachers and educators who are afraid and sceptical tow ards using social media and to show that there are positive attributes both educationally and socially. This study will try to present research and information that will promote a pedagogical use of Facebook as a social network 
and shed light on a more positive view on the way to exploit this network as an asset to education. Through a more oriented and guided education and finding adequate ways of using differently th is social medium, which is Facebook, it is mostly hoped that students and teachers could benefit both academically and socially.

\section{Problem of the study}

We are no more speaking about classical teachers who opt for blackboards and chalk in their process of teaching, but the role of teacher knows a constant mutation. Now adays, teachers are facing new challenges and changes, and thus, they are asked to cope with. In addition to that, schools are targeting modern and new methods of teaching and learning issued directly from modern and westernised approaches. The direct results are observable in the massive increase in the number of students as well as the explosion in the development of teaching with ICT and that is why teachers should update their technological knowledge and skills to develop the educational process in their classrooms and their countries.

The advent of social media, social networks and ICT has become a whole system that can control education processes if well used. With their role inside establishments and institutions, many studies and researches started investigating their roles and their effects in promoting interactive educational environments. These studies gave concrete proofs about their contribution in improving methods of teaching and positively enhancing the level of learners and teachers as well (Kennewell \& Beauchamp, 2007). It is noticeable that there are less studies focusing on the use of social networks and social media to create and develop a more interactive educational environment in teaching and learning. Their presence can help in developing thinking skills, making classrooms pleasant environments for the acquisition of knowledge and guiding students to develop critical thinking skills in different situations. (Al Hudhaifi \& Al Dughaim, 2005). All this means that teachers have to update their technological knowledge and competencies in order to develop the educational process inside classrooms, along with using ICT tools, social media and social networks. Teachers need to be motivated to do so and have to understand that the road of success passes through professional self-development.

\section{METHOD}

There is no doubt now adays that we are living in a volatile world, where it has become very difficult to get rid of technologies and ICT, or even to think about living without their presence. Consequently, while speaking about the use of social networks, which has become a universal phenomenon, it is weird to think about some people who are not yet taking full advantage of them. Students as well as teachers all over the world can connect from their computers, cell phones, iPods, and several other personal devices. They have become connected to the world as one family in a small village. Accordingly, as there are many advantages and disadvantages to these technological advances, there is no possibility to avoid the use of the technological tools, spaces and machines. Today's classrooms have developed into virtual and non- material environments, where teachers and students must get on board in order to connect with each other, be linked to one another and melt virtually (Taranto et al., 2011).

In the past, before the appearance and emergence of social networks, it was very difficult for people to communicate freely and instantly, as we were speaking about the concept of remote communities and distant exchanges. Thanks to social netw orks like Facebook, it has become possible and easy to be connected as one individual or group to other individuals or groups, inside virtual communities, where numerous people are tied into. Facebook has the largest basis of members in the world, where seven (7) out of every ten (10) people on the planet have a Facebook account or more. With these types of numbers, researchers like Roth (2009), Bosch (2009), and Holladay (2010) have begun to evaluate the use of social media, and mainly Facebook as pedagogical and instructional tools, in a new realm, which is education. (Siegle, 2011).

Research studies have presented facts that students worldwide learn more efficiently from their peers and tend to respect teachers who use mediums they are comfortable with and proficient in when providing instruction and teaching (Roth, 2009). It goes without saying that social networks may show to be a useful tool and medium for teachers in particular and educators in general. Roth (2009) states that when pedagogy is discussed, the teaching of the new generations of learners can be done better, if teacher s meet the needs of 
their learners on their terms, lest risking the failures to acquire knowledge via an unfamiliar medium and style. To date, my research has focused on the examination of the relevant literature and background appropriate to the study, aiming to contextualize the research to be undertaken. In this chapter, the research focuses on the methodological approach and philosophy that are the basis for the research itself. I have tried to consider the approach used in this study. In addition, in this chapter, I will try to discuss the study objectives, the target population and sample, and the reasons for the selection of a specific data collection tool. For this reason, I have developed one questionnaire that is explored here, discussing the reliability and validity and the analysis techniques associated with the questionnaire method.

Consequently, to further describe the role social media tools, such as Facebook, can play as pedagogical tools in the English classroom; this study will address the following questions:

- Research question 1: What are the attitudes and motivations of Moroccan English teachers tow ard the use of Facebook?

๑) Research question 2: Does Facebook strengthen the ties of learning between teachers and their students?

(-) Research question 3: How do Moroccan English teachers perceive the use of Facebook as a pedagogical and instructional tool?

๑) Research question 4: Can Facebook be a tool for teaching and learning?

\section{Population of the study}

Researchers Polit and Hungler (1999) refer to the population of a study as an aggregate or the totality of all the objects, subjects or members that are conform to a set of specifications and criteria. In our research study, the population was Moroccan English teachers from both sexes, differ ent age groups, different educational status, and different geographical places within Morocco, who were investigated about the use of social network Facebook as a pedagogical and instructional tool in the teaching of the English language in their classes.

\section{Sample of the study}

In our research study, a convenience random sample of 300 Moroccan English teachers has been obtained, from teachers who were chosen at random to take part in the survey about the use of Facebook as an instructional and pedagogical tool in the teaching of the English language. LoBiondo-Wood and Haber (1998) describe the convenience random sample as the utilisation of readily accessible persons in a research study. We found it easy as researchers to get participants from teachers, since each member of the population has an equal chance of being included in the sample. The obtained results can to a certain extent and degree be generalizable to the entire population of teachers.

Design of the study

The present study adopted only one research method including a quantitative approach, and exceptionally some participants were asked through some questionnaires that were administrated directly to them face to face. As a rule in such research, both quantitative and qualitative approaches should be taken into consideration when appropriate. However, the size of the chosen sample could not permit to introduce a qualitative approach such as the use of interviews, since there are 300 teachers who constitute the sample of the study, with different geographical locations and levels of teaching.

I have employed the questionnaire in order to provide a complete and clear picture of the area of research. Furthermore, this is critical to answer the aforementioned research questions relying on many advantages of this quantitative method. (Denscombe, 2010).

\section{Results of The Study}

The participating teachers were unanimous about this point. When asking them about the disadvantages that Facebook may have if used in teaching, they strongly disagreed that Facebook does not make teaching more difficult (45\%), as it does not decrease the students' motivation (45\%), does not limit the content of the teachers' lessons (46\%) and does not make the preparation of the lessons more difficult for 
them (47\%). However, about a quarter of the teachers strongly agreed that Facebook might have such disadvantages. In contrast to this, they were also asked about the advantages of using Facebook in teaching. They stated getting more confidence (55\%), diversity of lessons (59\%), quick preparation of lessons (55\%), fun lessons (58\%) and complementarity/ productivity of lessons (63\%).

Again, more than half of the teachers could agree and even strongly agree sometimes about the effects of Facebook on teachers and how this social network could help them to be motivated and to motivate their students. The teachers said that Facebook could help their students to better understand $(88 \%)$, socialize with their students by means of formal and informal teaching ( $88 \%)$, enhance their roles as teachers $(41 \%)$, make them feel professional $(81 \%)$, change positively the relationship between them and their students $(89 \%)$ and change positively the usual relationship between students in the classroom (89\%).

There are still some teachers who saw negative effects on using Facebook in teaching. Accordingly, $60 \%$ of the teachers said that Facebook might make them spend more time and energy on the preparation of their lessons and another $60 \%$ of the participating teachers declared that they could waste time if using Facebook in the classroom with their students.

One of the questions concerned the terms and benefits of using professional Facebook class pages. Teachers were agreeing that these class pages could be administrated by students who can be assigned the roles of content creators or moderators $(45 \%)$. These pages according to the same teachers can be used to review articles, audio and video lessons (95\%), brainstorming students about lessons' issues (94\%), posting comments by students (95\%) and posting related class content (96\%).

Some of the pre- class activities that were proposed to Moroccan English teachers include the quizzes and assignments, the contents and discussions and the post questions. Teachers agree in a big majority (95\%) that Facebook can amplify many class activities, especially when students can post questions before the class and save time when in class. Teachers also agreed that Facebook could be used to introduce lessons, content and discussions with other students or even with teachers (96\%). At last, the participating teachers could not be more aligned about the fact that one of Facebook pre- class activities that could be amplified is to remind the upcoming events such as quizzes and assignments (96\%).

Teachers find it difficult sometimes to ass students and the tasks they give them and they cannot get if the students understood or not. These teachers agreed that they could use Facebook to amplify during-class activities via Facebook. Teachers declared that one of the activities that might be used through Facebook is to post comments and questions and they all agreed on that with a rate of $92 \%$. Moreover, the teachers said that students could also share opinions and resources (91\%) without ha ving any problems and having fun as well as being motivated at the same time.

After reviewing pre- class and during- class activities and how they can be amplified via Facebook, teachers were invited to show their attitudes and perceptions as for using Facebook to amplify post- class activities. This phase concerns students and teachers as well. More than $91 \%$ of the teachers said that teachers could post homew ork when the lesson finishes via Facebook, or even send announcements about upcoming events (97\%). For students, they were seen by teachers to have the possibility of sharing their learning findings and discoveries (97\%) and post reflections and notes $(96 \%)$.

After proposing to the teachers the benefits and terms of using a Facebook class page, it is the turn of introducing the use of a Facebook class group. Rates were very high and there have been total agreements on the positive benefits of Facebook groups. Teachers said that these groups could be used to connect through virtual chats $(90 \%)$, to practice online discussion topics $(94 \%)$, to have access to course related material such as videos and articles (97\%) and even to conduct research through surveys and opinion polls $(48 \%)$.

Among the other features of Facebook, the teachers werejust positive and tot ally agreeing on a number of elements that make Facebook a pleasant space for teaching and learning. Accordingly, on Facebook teachers viewed that book reviews can be shared between students $(96 \%)$, class notes could be posted for absent students (89\%), class blogs can be included into the Facebook page/ group (89\%), class groups for writing students can be created (95\%) and also the possibility of creating Facebook groups for studying and revising (96\%). 
One of the components of Facebook is a special constituent called "Facebook Live". The main objective of this question is to measure the teachers' knowledge and use of "Facebook Live". Since it is a newly added option on Facebook, many teachers could not know what it was for neither its existence. Because of this, 57\% of the participating teachers said that they don't use Facebook Live, though they have a Facebook account and $11 \%$ of them declared that they even don't know what it is used for or its purpose and reason of being on Facebook. How ever, 32\% of the teachers knew it and were positive about using it, without précising the reasons for its use.

When asked about the possibility of using "Facebook Live" by their students and whether it could be useful to them, some teachers were clear and said that they could not know whether their students use "Facebook Live" or not, as they are not so close to them to that point. Then, $35 \%$ of the interview ees declared that their students might not use Facebook Live for academic and educational purposes but rather for personal aims. At last, the big majority of teachers (55\%) were positive and went for the use of their students of "Facebook Live", believing that it can motivate them in the learning of English through modern ways, especially when it comes to the enhancement of speaking and listening.

Moroccan teachers presented their views concerning the benefits of Facebook Live. They said that this tool is a revolutionary one and can be used for a number of positive reasons, such as enhancing speaking activities (20\%), improving listening activities (20\%), encouraging shy students for a better interaction (18\%), beside revising already studied contents with other students or even with the teacher, or even keeping a trace or a record $(13 \%)$.

Teachers said also that "Facebook Live" could be used by teachers as well as by the students in many ways. One of the ways where the main benefits of "Facebook Live" can be exploited is the deliverance of presentations, either directly or through recording them and presenting them later via the Facebook platform. Less than half of the teachers $(41 \%)$ said that students could use "Facebook Live" to deliver the presentations to avoid shyness in front of the public and to have more time for reflexion. Another $39 \%$ of the teachers said that students would not be able to present through the tool as they do not present inside the classroom, since they are not motivated.

The question of what benefits to gain from presenting through "Facebook Live" was also asked to teachers. The main benefits agreed upon by the teachers were being self- confident (24\%), being at ease while speaking (24\%), having more time to think and control the topic $(20 \%)$ and avoiding shyness in addition to being introvert (16\%).

\section{Discussion}

We tried so far in our research study tries modestly to shed light on the results that were obtained after asking the teachers about the advantages and the disadvantages of using Facebook in teaching by Moroccan English teachers. These data are changing and will be seen differently by the participants. All the elements were ranged on a Likert scale of five levels, going from "Strongly disagree" to "Strongly Agree". When it comes to speaking about the advantages of using Facebook in teaching, there are many elements that seem to attract the attention of the teachers and that they might want to focus on while experiencing Facebook with their students. One of the advantages concerns the complementarity between the classroom activities and Facebook, as this latter will be an addition and a complem ent of what the teacher does with his students in the class, either before the lesson, while doing it or after it. The teachers went from agreeing (63\%) to strongly agreeing $(23 \%)$ about this point. Another major advantage is concerned with the fact of post ing contents on Facebook before learning them in class in a more productive way, which is a point that goes hand in hand with the first advantage, and here again, the teachers agreed unanimously (83\%), as they perceived this advantage as one of the strong points of Facebook. Teachers' perceptions about using Facebook in the teaching process gathered also other advantages. For instance, teachers agreed on the following points. Facebook makes the lessons more fun for students and motivates them to learn better the English language ( $84 \%)$, through applications that can be integrated by the teachers, the exchanges that can take a personal dimension and the educational games that can be played via the Facebook platform and that are already set in advance. The diversity of the content and of the lessons was also mentioned as an advantage, when using Facebook as a pedagogical tool for teaching. The teachers agreed and even in a strong manner about this point $(83 \%)$, as they said that Facebook has got a large set of r esources to exploit 
and even there can be a possibility of exporting and linking other resources from other social networking sites, such as YouTube, Instagram and Twitter. The disadvantages however of using Facebook in teaching were viewed by teachers as quasi-inexistent or rare for the time they were interviewed. The teachers disagreed (57\%) that Facebook might make their teaching more difficult, and said that it was totally the opposite case, as Facebook facilitates the process for teaching as far as teachers are concerned and for learning when students are concerned. The teachers disagreed also on other elements such as the decrease of students' motivation (63\%), the limitation of the content of the lessons for teachers $(59 \%)$ and the fact of making the preparation of lessons by teachers more difficult $(57 \%)$. The attitudes and perceptions of teachers when potentially using Facebook in teaching were viewed also from the angle of the effects of the Facebook social netw ork on the teachers as practitioners and agents of change inside the classroom, the school and the community. There were many elements that were targeted, but some of them were similar. Teachers agreed that Facebook could change positively the learning climate in their classrooms (69\%), for their students and for themselves. They justified this fact by saying that when students are inside the classroom, they feel a certain burden and cannot concentrate very well, especially in mixed and crowded places, while on Facebook they take it easy and are more self-confident expressing themselves and getting better results. This way, the usual relationship between students themselves $(65 \%)$ on the one hand and between teachers and students $(65 \%)$, will be positively changed. Other positive effects that teachers considered while thinking about using Facebook in their classrooms concern the act of socializing with students and moving from the formal atmosphere to the informal one. About $64 \%$ of the teachers agreed that it is possible; in case of a wellset strategy of use. This will also affect the understanding of students who would understand better (63\%), if they find themselves in a free anxiety environment, with much motivation and more emphasis on the social side of the teaching and learning process. The negative or less desired effects that Facebook might engender according to the teachers would concern them as individuals doing their job, more than being teachers. A percentage of $60 \%$ of the teachers agreed that while working with Facebook as a platfor $m$ for conveying tasks and activities, they could spend more energy in the preparation of lessons $(60 \%)$ and they would also need to look for resources before, as well as put a plan of work, but before all this, they need to master the Facebook platform itself, to use it adequately and efficiently. Additionally, they even agreed that while working on Facebook for a pedagogical cause, they would waste more time $(60 \%)$ than they do while working the classic way. In fact, they even said that because a great major ity could not think about making an extra effort to prepare and to innovate using modern tools and technological sets. Teachers' perceptions about the use of one of Facebook components is different in terms the utility and the benefits. This component is the Facebook page for a given class, with a number of students. According to the participating teachers, once the page of the class is set on Facebook, students can themselves post comments, as there is an option, which might stop them from posting and be contented to reading other comments without replying. Teachers agreed at $76 \%$ on this option and they even added that it is true that the Facebook class page can be used to brainstorm the students about the coming or the past lesson issues (74\%) and it is one of the important uses, since students would understand better the lesson, if they are in the after lesson phase or they will be prepared to discuss the upcoming lesson, if they are in the before lesson phase. This act of brainstorming and reviewing does not only concern the lessons, but it includes also the review of audio as well as video lessons and articles (71\%). The teacher might use the page in varied ways and he might assign the role of the administrator or the co- administrator to one or several students who could help him and organise the work efficiently. As mentioned before, any lesson can be divided into three phases. The preclass phase, the during class phase and the post class phase. Each one of these phases comprises a number of activities. For the amplification of the pre- class activities via the Facebook platform, the teachers were clear about the different advantages of using a class page. For instance, teachers agreed that students can post questions before the class (59\%) and teachers can answer the questions back, or even other students. Additionally, the teachers agreed at $63 \%$ that they could resort to the introduction of lessons, content and even initiate discussions with their students or with other invited colleagues. This fact is often done by teachers and not by the students who are invited to take part in such activities. Thus, sometimes, the Facebook class page could be used by teachers and even students, in a similar way, to remind other students about upcoming events, such as quizzes and assignments (61\%). These pre- class activities could be improved and modified with other activities that concern the teachers and the students as well. 
The during class activities that were discussed in our observation and were proposed to teachers concern the posting of comments and questions, in addition to sharing the opinions and resources during the class. Again, the Moroccan English teachers agreed and sometimes strongly did about the benefit of the Facebook class page, when working on these. About $60 \%$ of the teachers agreed and another $32 \%$ strongly agreed on both activities. The teachers said that the main problem that they encounter in the class is the lack of communication and exchange between students themselves or between the teacher and the students, that is why, they would find it easy to use the class page to talk, discuss and share their opinions about a certain component or a certain lesson, they did not understand or they would like to bring further explanations or developments. The teachers, and in order to complete the last activities concerning the post- class, they perceived the use of Facebook class pages to amplify them, were proposed four elements, in order to measure the efficiency and usefulness of the Facebook page. As already done with pre- class activities, the participating teachers agreed that such pages could be used to send announcements about upcoming events (69\%) such as further tasks, extra activities, resit for exams and tests, summaries for absent students, homew ork, reflections and even live recordings for students. Even the students, might use this class page on Facebook at the end of any lesson to try to share their learning findings and discoveries (67\%) or even to post questions about matters they did not understand in the class, and that can be answered and replied to by the teacher on the page. Facebook has another component, which can be very beneficial for students and teachers as well. This component is the Facebook class group, which is similar to the Facebook class page. The teachers considered that the same activities that could be amplified via a page could be done through the Facebook class group. However, there are other components in the page that we wanted to examine and to know the teachers' perceptions concerning them.

As usual, the teachers agreed to the highest point about the benefits of using the class group. This group can be used to get access to related material such as videos and articles, according to teachers who agreed on that $(69 \%)$. They said that this operation needs some training, both for teachers and for their students. This can be also, according to them, a complement for lessons either before starting them or after finishing them. Teachers added that through a Facebook class group, the students and the teachers can participate online through discussion in topics that are important for them $(68 \%)$, either via the direct chat or the video live chat, without forgetting the importance of setting private parameters to keep the group "CLOSED" (63\%) and not to give access to other students or individuals from outside the class. The group will be a private one for the students of a given and specific class of students with their own teacher or even many teachers, teaching the same subject or different subjects. At last, the teachers, and in order to see whether the students understood the lesson, have inquiries or comments about any given detail or set of details, strongly agreed (29\%) that they could conduct a research through an additional component that is the "POLL", through which they would see how many people agree or disagree about something. Alternatively, the teachers can design and conceive an online survey, get the sharable link and post it on the group, then; they can ask their students to complete it. The Moroccan English teachers' attitudes and perceptions concerning the previous components and elements seem to be all clear and positive with high agreements on using different characteristics and options of Facebook. At last, they completed their agreement about the positive sides of using Facebook in teaching, concerning other features. Teachers saw it a good idea to use Facebook to create special pages for projects $(62 \%)$ where they can work collaboratively and exchange views and ideas, to create special groups for writers among students (61\%), as some of them have a special passion for writing and through the group, they can learn more and develop their skills, by comparing their productions with other students and even send their work to the teacher, who might play the role of the supervisor of the group. A last idea, that seemed possible but weird for teachers, was related to the implication of parents and getting in touch with them. Teachers agreed at $57 \%$ that parents cou ld play a role of motivators and incentives to push them for better results. How ever, this idea was refused by many, as it seemed to be an intrusion of a foreign element, which could be a hindrance to the positive process of acquisition of the English language.

The question targeting the use of Facebook live by Moroccan English teachers was just focusing on knowing the personal aspect and not the pedagogical one. It $w$ as thus expected that the teachers would not 
have a knowledge about "Facebook Live", since it is a new service that was launched by the social network Facebook in 2015. The statistics show that $57 \%$ of the participating teachers do not use Facebook Live for personal purposes, whereas $32 \%$ use it as part of a Facebook technological service that is offered freely to them. These teachers say that they started using it with family and friends for fun and for entertainment. A third category admitted that they do not even know what the Facebook Live service is. Actually, the teachers are not the only ones who are concerned by the use of Facebook Live. Students are also targeted by a similar question that is asked to the teachers in order to know the possibility of use by students, though this question seems a little bit out of context but it was necessary to measure the knowledge of the teachers of their students. A percentage of $55 \%$ of the teachers said that their students use the Facebook Live service, either to record themselves and post that for funny purposes and for entertainment aims, or to just record other people doing things that can be considered by other people as amazing or out of the normal. These teachers asked their students whether they have ever used Facebook Live for educational purposes or for assignments given by their teachers in any one of the subjects, they replied that no.

Teachers said also that their students could have the possibility to deliver presentation and talks through the Facebook Live tool (41\%) and that is a kind of testimony from these teachers that their students are able to use this technological tool without problems. The benefits that they would gain according to the participating teachers are varied and multiple, but they wanted to insist on three paramount benefits. The first benefit concerns the use of Facebook Live to face shyness and to gain more self- confidence (24\%). The second benefit is related to the ease while speaking $(24 \%)$, since students face sometimes stage fright, stress and anxiety and a third benefit is the possibility to have more time for students to think and control their topic, since the Facebook Live service stands on the fact of recording, and this cannot be done without a previous preparation and a predisposition. Whereas a last category of teachers (39\%) said that their students would not be able to do that, since they are not skilled enough to do that, or because they are afraid sometimes to be exposed on line.

\section{Limitations and Delimitations}

The purpose of this study is mainly to explore the impact of Facebook as a pedagogical and as an instructional tool and its use by Moroccan English teachers in their classrooms. For our research study, a number of participants constituted of 300 Moroccan English teachers belonging to different teaching cycles and from different geographical horizons in Morocco. Their choice was done at random, either through direct interaction with some of them in different events and scientific meetings, or through sending them the electronic forms and asking them to fill them in. Many limitations could be inferred while conducting the study. Here are some of them. The use of the questionnaire in gathering views and knowing the perceptions of teachers as far as Facebook and its use as a pedagogical tool in teaching is a good quantitative way of analysis and data collection. However, it would have been preferable to focus more and take a bigger population while doing the direct administration of the questionnaire. It is said and argued by most researchers that the qualitative the study is, the accurate and more precise it will be in terms of results and recommendations. We conducted some interviews with some participants, but they were not considered as real ones, nor were they analysed according to transcripts or special norms related to the qualitative research itself. Many teachers added remarks at the bottom of the questionnaires papers, and so, they could have expressed themselves directly in the presence of real interviews.

It is true that the questionnaire could havebeen sent automatically to the 300 teachers in their e-mails or via other social networks, but it would have taken more time, and more risks could be associated in biasing the answers. Moreover, we did not have all the emails of the participating teachers. May be it could be done for future studies with a larger population and with an exact list of mails of teachers, handed out by the educational authorities in the ministry of education, as every teacher has his own professional email. We faced also some obstacles in transforming the questionnaire from the paper format version to the electronic format, as many questions that were put in tables were split into other sub- questions in the electronic version when using the software "Google Forms", and consequently, the number of questions raised, letting us think that many teachers would hesitate to answer when they will see a big number of questions. It has also a repercussion on the treatment of these questions in the treatment software "Sphinx", since it was necessary to divide sections and sub sections and to be careful not to make a mistake while designing, as it would be very difficult to repeat all the work, when we will be in the phase of the analysis. We have chosen 
Soulaymani,S. \& Alem,N.(2018).Perceptions of Moroccan English teachers towards using Facebook as a pedagogical and ins tructional tool. International Journal of Educational Research Review,4(1), 33-43.

not to include the qualitative research methodology, as we believe that we have a large population from different teaching environments on the one hand, and because of the geographical settings of the participants who are from the four regions of Morocco. Accordingly, our main aim was to choose the teachers as a main population, as our study considers them as the source and the engine for any pedagogical act or operation. We could have chosen the students as well, but it can be done in further studies, to compare and to illustrate the traits of comparison and differences between the two.

\section{REFERENCES}

Al Hudhaifi, K.F. and Aldoghaim, K.I. (2005). The effect of teaching chemistry by using computer on developing scientific thinking and attitude towards chemistry among high school students', Journal of Studies in Curriculum and Teaching Methods, 103, 137-194.

Aricak, O. T. (2009). Psychiatric symptomatology as a predictor of cyberbullying among university students. Egitim Arastirmalari-Eurasian Journal of Educational Research, 34, 167-184.

Basque, J. (1996). Stratégies d'intégration des technologies de l'information et des Communications à l'école, Document de la collection L'École informatisée Clés en main. Montréal : Ministère de l'Éducation du Québec.15 pp. (Publié également en anglais). Consulted on 03/12/2010. Disponible sur : Http://www.grenoble.iufm.fr/rural/pradel/doc/tice.htm

Bramble, N. (2010). Éducation: Facebook doit entrer à l'école. Pourquoi les écoles ne doivent plus bloquer l'accès aux réseaux sociaux. Accessible en ligne (3 janvier 2010) : Http://www .slate.fr/story/15159/facebook-ecoleeducation-outilpedagogique-enseignement-reseaux-sociaux.

British Educational Communications and Technology Agency (BECTA) (2008). Harnessing technology: Schools survey2008.Retrieved at:

Http://emergingtechnologies.becta.org.uk/uploaddir/downloads/page_documents/research/ht_schoo 1s_survey08_analysis.pdf

Denscombe, M. (2010). The good research guide, maidenhead: Open University Press. (P 283)

Ertmer, P. (1999). Addressing first- and second- order barriers to change: Strategies for technology integration. Educational Technology Research And Development, 47(4), 47-61.

Guttman, C.. L'éducation dans et pour la société de l'information. Genève : Publications de l'UNESCO pour le Sommet mondial sur la société de l'information.

Holladay, J. (2010). Cyberbullying the stakes have never been higher for studentsor schools. Teaching Tolerance, 38, 42-45.

Kennewell, S.H., and Beauchamp, G. (2007) Analysing the use of interactive technology to implement interactive teaching, Sw ansea, UK: Sw ansea School of Education \& Sw ansea Institute of Higher Education.

LoBiondo-Wood, G., \& Haber, J. (1998). Methods and critical appraisal for evidence-based practice. Elsevier Health Sciences. 
Soulaymani,S. \& Alem,N.(2018).Perceptions of Moroccan English teachers towards using Facebook as a pedagogical and ins tructional tool. International Journal of Educational Research Review,4(1), 33-43.

Polit, D.F. \& Hungler, B.P. (1999) Nursing Research: Principles and Methods $6^{\text {th }}$ ed. Philadelphia: J.B. Lippincott

Roth, D. (2009). Following Plato's advice: Pedagogy and technology for the Facebook generation. Journal of Philosophy and History of Education, 59, 125-127.

Siegle, D. (2011). Facing facebook: A guide for non-teens. Gifted Child Today, 34(2), 14-19.

Taranto, G., Dalbon, M., \& Gaetamo, J. (2011). Academic social netw orking brings Web 2.0 technologies to middle grades. Middle School Journal, 42 (5), 12-19. 